\title{
Experimental Analysis of Simplified Rules Fuzzy Logic Speed Controller for Wide Speed Range Operations
}

\author{
M. H. N Talib, Z. Ibrahim, Z. Rasin, J. Mat Lazi, M. Azri, N. S. Y. Farah \\ Centre for Robotics and Industrial Automation (CeRIA), Fakulti Kejuruteraan Elektrik (FKE), Universiti Teknikal \\ Malaysia Melaka (UTeM), Malaysia
}

\section{Article Info \\ Article history: \\ Received Apr 14, 2018 \\ Revised Jul 22, 2018 \\ Accepted Aug 6, 2018 \\ Keyword: \\ Fuzzy Logic Control Induction Motor Drive Scaling Factor Simplified Rules Speed Controller}

\begin{abstract}
This paper presents the experimental analysis of simplified rules Fuzzy Logic Speed Controller (FLSC) of Induction Motor drive. The maximum gain of input scaling factor, FLSC is generally limited by the coverage of universe of discoursed (UoD). Thus, to further increase the input gain scaling factor, $\mathrm{G}_{\mathrm{e}}$ the outer membership function need to be increased. This analysis covers various $G_{e}$ values in the range of $\mathrm{UoD}$ values from $[-1,1]$ to $[-5,5]$ for the wide speed range operations from low to rated speed ranges. The FLSC is employed to the indirect Field Oriented Control method fed by a voltage source inverter. Simulation and experimental verification is done by using Matlab/Simulink and dSPACE 1103 controller experimental rigs respectively. Based on the results, speed performance behaviours are improved over the wide speed range operations in term of rise time and setting time. The tuning approached is simple without additional algorithm for faster and more accurate response.
\end{abstract}

Copyright @ 2018 Institute of Advanced Engineering and Science. All rights reserved.

\section{Corresponding Author:}

M.H.N Talib,

Fakulti Kejuruteraan Elektrik,

Universiti Teknikal Malaysia Melaka (UTeM,

Hang Tuah Jaya, 76100 Durian Tunggal, Melaka, Malaysia

Email: hairulnizam@utem.edu.,my

\section{INTRODUCTION}

The popularity of the Fuzzy Logic Controller (FLC) is increased because of its ability to handle non linearity, disturbances and improved robustness [1-3]. The tuning of the controller however involves various parameters such as scaling factors (SF), membership function (MF) and decision rules. In fact, tuning of FLC is more complicated compared to the conventional PI controller due to many parameters involved $[4,5]$. A change in one of these parameters can significantly affect the overall performance [6,7]. Among these parameters, tuning the SFs has the highest priority in the tuning of the FLC effectiveness and greatly influences the FLC performance $[6,8]$. However, there is no standard of tuning procedures for FLSC scheme like PI controllers.

In most cases, the scaling factor gains are tuned based on the normalized value of the universe of discourse (UoD) $[1,9,10]$. Under normalized value the universe of discourse (UoD) range is commonly set at $[-1,1]$. Thus, the maximum input gain scaling factor, $G_{e}$ is relatively small and limited based on this condition. As a result, fast speed response cannot be obtained. Majority of the previous research work, the optimum performance is achieved by tuning the MF parameters. Tuning the MFs mainly involves in adjusting the type, shape, nonlinearity and distribution of MFs [9-14]. In addition, the analysis is limited only at the rated speed range operation. No details analysis discussed on the wide speed range operation or the behavior of the speed controller performance.

Zheng et. al (1992) prescribed the tuning methodology between the parameters and performance [4]. From the discussion, tuning the SFs changes the definition of the MFs and consequently gives a significant 
effect to all control rules. From this statement, it is important to tune the SFs followed by the MFs tuning. However, there is no systematic procedure for FLC designed algorithm as well as the determination of scaling factor [15].

Some of the previous researchers also applied different range of UoD for the speed error such as more than [-1,1] of UoD [15-19]. However, the discussions of the selected range and the input variable or fuzzy subsets distribution are not discovered. Ming et all also applied higher range of UoD for speed error [20]. The maximum range is set at $[-6,6]$ determined based on the maximum speed of the motor. The fuzzy subsets distributions of the input variable are equally distributed with symmetrical and 50\% overlapping rate. However, this combination is believed to produce similar performance results with normalized UoD by adjusting the input scaling factor gain. In addition, there is no detail study on the inputs scaling factor tuning effect over a bigger range of UoD. From this hypothesis, the study of influence of the inputs scaling factor is conducted.

This paper investigates the influence of inputs scaling factor and universe of discourse (UoD) towards the speed performance in wide speed range operations. The UoD covers from $[-1,1]$ to $[-5,5]$ domain. The influences of the inputs gain variation are then investigated under rated and wide speed range operations. Simulation and experimental results are presented to validate the performance effects. The proposed input scaling tuning method has shown better controlling ability during transient and steady state performance. In addition, the analysis covers wide speed range operation from low to high speed operations empirically.

\section{INDUCTION MOTOR DRIVE}

The block diagram of the FLSC with indirect field oriented control of induction motor drive is shown in Figure 1. The drive system consists of induction motor, coordinate transformation, voltage source inverter, current controllers and speed controller.

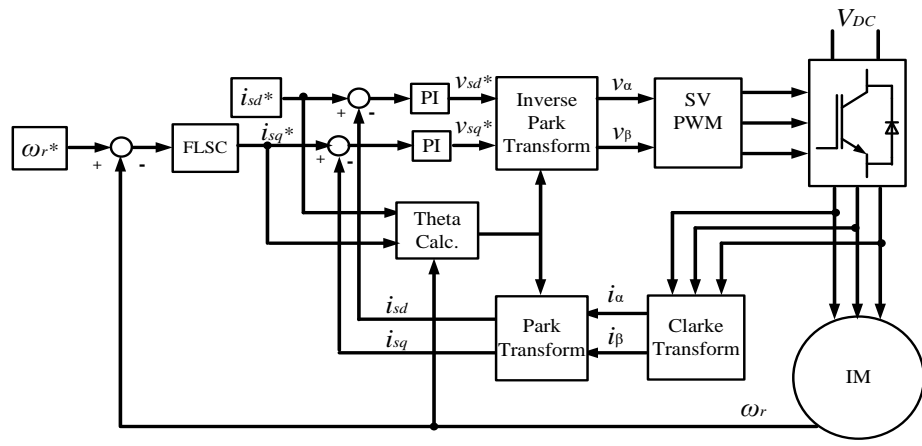

Figure 1. FLSC with indirect FOC method block diagram

The mathematical model of the three phase induction motor in synchronous reference frame is given in [21]. The voltage source inverter is controlled by mean of the Space Vector Pulse Width Modulation (SVPWM) method. Based on the indirect FOC principle, the rotor flux angle, $\theta_{\mathrm{e}}$ for coordinate transformation is generated from the integration of rotor speed, $\omega_{\mathrm{r}}$ and slip frequency, $\omega_{\mathrm{sl}}$ as shown in Equation (1).

$$
\theta_{e}=\int\left(\omega_{r}+\omega_{s l}\right) d t
$$

The slip frequency is calculate by using equation (2) below and included in theta calculation block.

$$
\omega_{s l}=\frac{L_{m}}{\tau_{r}} \frac{i_{s q}}{\varphi_{r}}
$$

The error between reference rotor speed, $\omega_{\mathrm{r}}^{*}$ and actual rotor speed, $\omega_{\mathrm{r}}$ is processed in the FLSC. The controller generates the $\mathrm{q}$ axis reference current, $\mathrm{i}_{\mathrm{sq}}^{*}$. Meanwhile, a constant $\mathrm{d}$ axis reference current, $\mathrm{i}_{\mathrm{sd}}^{*}$ is set for the input reference. Both $\mathrm{d}$-axis and q-axis stator current error are then regulated by the proportion integral (PI) controllers. These PI parameters are kept consistence in order to analysis the FLSC performance. 


\section{FLSC STRUCTURE}

In general, a standard block diagram of the FLSC structure is shown in Figure 2. The controller consists of pre-processing, FLC and post-processing. The Mamdani system FLC structure has four main components that are fuzzification interface, fuzzy rules, inference engine and defuzzification interface. The fuzzy rules and the inference engine are the decision making part of this artificial brain. The fuzzification converts the crisp input to suitable linguistic rules and the defuzzification block converts back from the fuzzy output to crisp output. For the standard PI like FLC configuration, two input variables are used for speed error and change of speed error; and one output variable is changed at the output control.

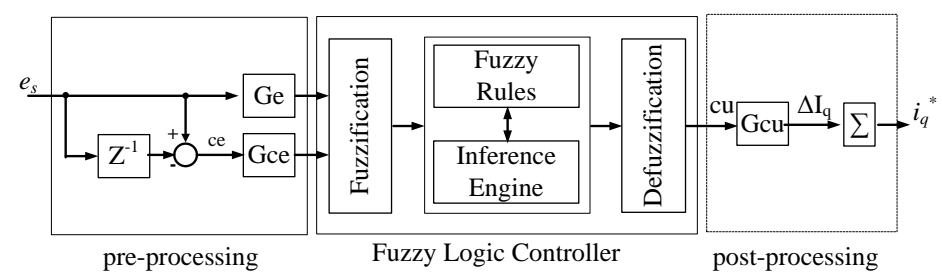

(FLC)

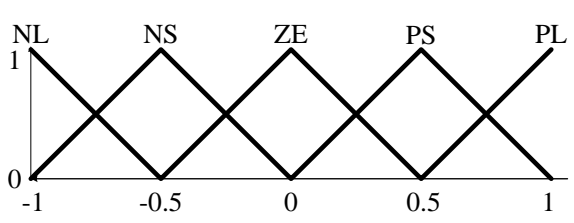

Figure 3. 5x5 MFs for e, ce and cu

Figure 2. Standard FLSC block diagram

In pre-processing part, two fuzzy inputs variable for the controller are computed as presented by Equation (3).

$$
\begin{aligned}
& e(k)=G_{e}\left(\omega_{r}^{*}(k)-\omega_{r}(k)\right)=G_{e}(k) \\
& \Delta e(k)=G_{c e} \frac{(e(k)-e(k-1))}{T_{s}}
\end{aligned}
$$

The inputs scaling factors (SF), $G_{e}$ and $G_{c e}$ are the gain for speed error and change of speed error respectively. Meanwhile, $\omega_{\mathrm{r}}^{*}$ and $\omega_{\mathrm{r}}$ represent the reference and actual motor speed respectively. Indices $(\mathrm{k})$ and (k-1) represent the current and previous state of the system respectively to obtain the change of speed error, ce based on the sampling time $\mathrm{T}_{\mathrm{s}}$.

In this paper, $5 \times 5$ MFs matrixes are used for error, change of error and output incremental variables as shown in Figure 3. The symmetrical triangles are equally distributed with $50 \%$ overlap between the adjacent MFs. The inputs and output variables are normalized in [-1,1] domain. The MFs are named as Negative Large (NL), Negative Small (NS), Zero Error (ZE), Positive Small (PS) and Positive Large (PL).

In order to achieve high sampling rate for the real time implementation, the number of rules need to be reduced. Simplified rules method is performed to the $5 \times 5$ MFs rules based matrix as discussed in [22]. Based on the simplified rules method, only 7 rules are chosen out of the 25 rules. Through the simplification process, the computational time is reduced and the speed performance does not degraded. Figure 4 shows the $5 \times 5$ MFs rules matrix and selected simplified 7 rules.

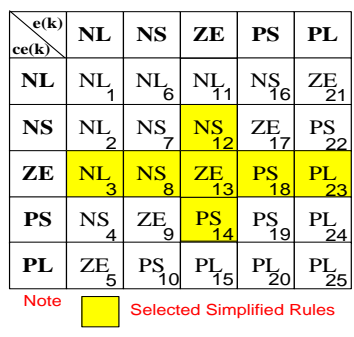

(a) $5 \times 5$ MFs rules matrix

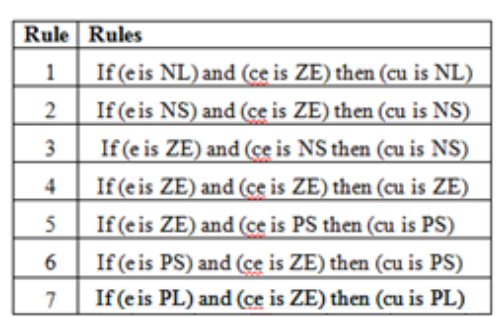

(b)Selected 7 rules

Figure 4. Selected rules for simplified FLSC

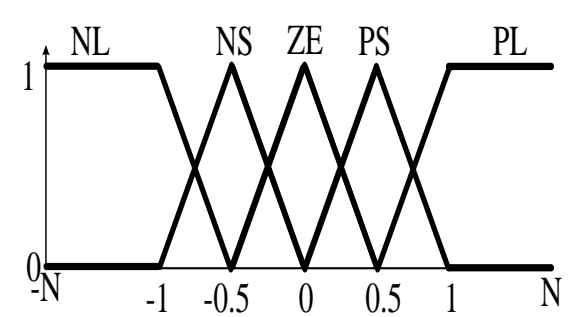

Figure 5. Modified MFs distribution for $\mathrm{N}$ multiplication factor of change of speed error SF 
For the post-processing part, the incremental of output control, $\Delta \mathrm{i}_{\mathrm{q}}^{*}$ is compute by using center of gravity (COG) algorithm. The final output current signal demand, $\mathrm{i}_{\mathrm{q}}^{*}$ can be obtained by multiplying the $\Delta \mathrm{i}_{\mathrm{q}}^{*}$ with the output scaling factor, Gcu as written in Equation (4):

$$
i_{q}^{*}(k)=i_{q}^{*}(k-1)+G_{c u}\left(\Delta i_{q}^{*}(k)\right)
$$

\subsection{Initial Input Scaling Factor Parameters}

The initial value of speed error gain $G_{e}$ scaling factor (SF) are computed based on the maximum speed error $\left(\omega_{\text {emax }}\right)$ when the motor drive operates from standstill to the rated speed. In order to cover the forward to reverse operation, multiplication of 2 is applied. Thus, the maximum $G_{e}$ can be determined by equation (5) [23]. Based on this condition, the maximum range of speed error, $e$ MFs is normalized to [-1,1]. By taking the maximum rated speed for the induction motor at $149.7 \mathrm{rad} / \mathrm{s}$, the $G_{e}$ is 0.00334 .

$$
G_{e}=\frac{1}{\left|2 \omega_{\text {emax }}\right|}=0.00334(\mathrm{rad} / \mathrm{s})^{-1}
$$

The initial value of change of speed error gain, $G_{c e}$ scaling factor is determined based on the electrical and mechanical torque equations. Based on the electrical Equation in (6), the maximum torque can be determined as:

$$
T_{\max }=\frac{3}{2} \frac{P}{2} \frac{L_{m}^{2}}{L_{r}} i_{s d}^{\max } i_{s q}^{\max }=17.14 N m
$$

where $i_{s d}^{\max }$ is the reference flux current component at no load condition and $i_{s q}^{\max }$ is the maximum torque current component. The maximum torque current is assumed to be double of the rated current [5, 23]. By neglecting the external load and friction parameter of the motor mechanical torque equation, the maximum torque is directly proportional to the maximum change of speed error for sampling time, $T_{s t}$, given by Equation (7) below [5]:

$$
T_{\max }=\frac{2}{P} \frac{J\left(\Delta \omega_{\max }\right)}{T_{s t}}
$$

where $T_{s t}$ is the sampling time based on the encoder sampling time, $\mathrm{J}$ is the total inertia, and $P$ is the motor poles. Based on equation (8), the maximum magnitude change of speed error is calculated as

$$
\Delta \omega_{\max }=\frac{P\left(T_{\max }\right)\left(T_{s t}\right)}{2(J)}=\frac{4(17.14)(1.5 \mathrm{~m})}{2(0.02)}=2.571 \mathrm{rad} / \mathrm{s}
$$

Finally the initial scaling factor for change of speed error, $G_{c e}$ is calculated based on Equation (9).

$$
G_{c e}=\frac{1}{\Delta \omega_{\max }}=\frac{1}{2.571}=0.389(\mathrm{rad} / \mathrm{s})^{-1}
$$

For analysis, the performance design criteria is set at $100 \mathrm{rpm}$ overshoots with fastest rise and settling time. The $G_{e}$ is fixed at the maximum value as calculated in Equation (3) for the fastest speed response. Only the $G_{c e}$ gain is tuned to achieve the design criteria. After tuning, the final results of $G_{c e}$ is 0.2 . The controller for this inputs scaling factor is denoted as $\mathrm{S} 7(\mathrm{UoD} \pm 1)$.

\subsection{Adjustment of Input Scaling Factor Parameters}

In order to investigate the influence of inputs scaling factor gains, the $G_{e}$ and UoD domain for the error input variable MFs need to be adjusted accordingly. Further increase of $G_{e}$ value without adjusting the UoD domain of the error input variable MF produces uncontrolled speed operation especially during reverse operation.

First modification is made by increasing the $G_{e}$ value by multiplication of two, which double up the initial $G_{e}$ value gain of the reference controller $\mathrm{S} 7(\mathrm{UoD} \pm 1)$. The new $\mathrm{G}_{\mathrm{e}}$ can be determined by using Equation (10).

$$
G_{e}=\frac{1}{\left|\omega_{\text {emax }}\right|}
$$


Consequently, increasing the $\mathrm{G}_{\mathrm{e}}$ gain value requires an adjustment of the speed error input variable MFs parameter. The outer width of the trapezoid shape MF which are label as NL and PL is extended from 1 to 2 . Based on this approach, the range of the UoD domain for error input variable is increased from $[-1,1]$ to [-2,2]. Thus, it encompasses a wide width range from 0.5 to 2.0 for PL instead of 0.5 to 1 width range at previous setup. Meanwhile, the MF width for NL is set from -0.5 to -2.0. The other MFs component widths are remained unchanged. This requirement is necessary to cover wide speed range operation from rated forward to rated reverse speed demand. Figure 5 depicts the modified MF distribution for speed error intended for this improvement. The MFs for change of speed error, ce and output control action, cu remained unchanged at the previous design setup under UoD of $[-1,1]$. Based on this procedure, the final values for $G_{e}$ and $G_{c e}$ for $\mathrm{S} 7(\mathrm{UoD} \pm 2)$ are 0.00668 and 0.266 respectively. Further determination of maximum gain value for $G_{e}$ and $G_{c e}$ applies a similar procedure. The multiplication of $G_{e}$ gains are determined based on Equation $(11)$,

$$
G_{e}=n x G_{e}
$$

where $n$ is the multiplication factors for the $G_{e}$ gain from 1,2,3..n. Consequently, this multiplication also involves in changing the NL and PL value as shown in Figure 5. Finally, the $G_{c e}$ SF is tuned to obtain the required design specification performance.

\section{RESULT AND DISCUSSION}

Several tests are conducted to investigate the performance of the speed under the proposed of inputs scaling factor tuning method. The parameters for the 4 poles, $1.5 \mathrm{~kW}, 380 \mathrm{~V}$ three phase squirrel cage induction motor used in this work are given in Appendix A. Simulation study of induction motor drive performance is implemented in MATLAB/Simulink software. The simulation results are then validated by using induction motor drive experimental rig by using dSAPCE 1103 controller. Figure 6 shows the hardware experimental setup for the drive system. The simulation and experimental parameters are set to be the same. Switching frequency of $8 \mathrm{kHz}$ is used for the space vector PWM. The overall sampling time is $50 \mu \mathrm{s}$.

\subsection{Operation under no-load condition}

The variation of input scaling factor controller are named from $\mathrm{S} 7(\mathrm{UoD} \pm 1)$ to $\mathrm{S} 7(\mathrm{UoD} \pm 5)$, representing the multiple of $G_{e}$ scaling factor from 1 to 5. The $G_{c e}$ is tuned accordingly to achieve $100 \mathrm{rpm}$ design criteria at rated speed operation.

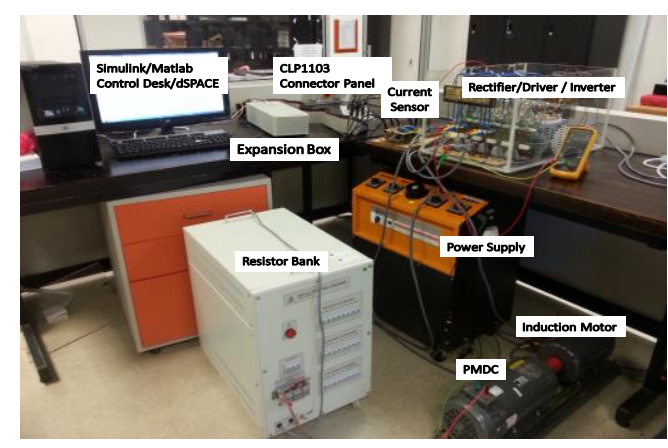

Figure 6. Hardware Experimental Setup

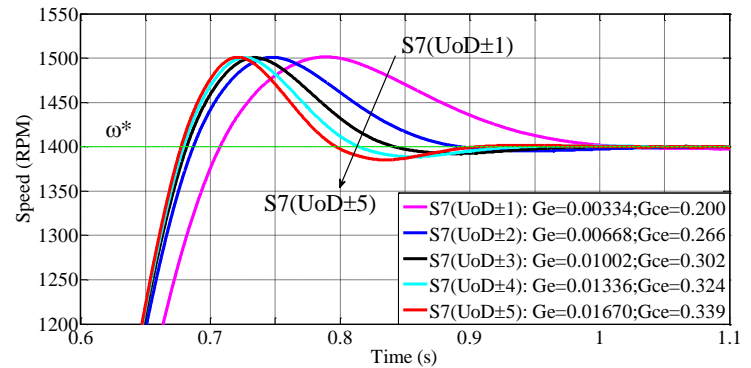

Figure 7. Speed response for different values of inputs SFs at rated no load speed operations

Figure 7 shows the close up view of simulation results from standstill to rated speed reference based on various inputs SF controllers at no load operation. The simulation is conducted in $2 \mathrm{~s}$ and the step speed demand is applied at $0.5 \mathrm{~s}$ from zero to rated $1400 \mathrm{rpm}$. Based on the results, $\mathrm{S} 7(\mathrm{UoD} \pm 5)$ produces faster rise time response and $\mathrm{S} 7(\mathrm{UoD} \pm 1)$ results in slowest rise time response with $0.1775 \mathrm{~s}$ and $0.2074 \mathrm{~s}$ respectively. Further increase of inputs gain over 5 multiplications however results in slower impact of rise time and settling time. For example, the rise time improves to $0.0206 \mathrm{~s}$ between $\mathrm{S} 7(\mathrm{UoD} \pm 1)$ and $\mathrm{S} 7(\mathrm{UoD} \pm 2)$. Meanwhile, the rise time improves only 0.0018 s between $S 7(\mathrm{UoD} \pm 4)$ and $\mathrm{S} 7(\mathrm{UoD} \pm 5)$. The higher inputs $\mathrm{SFs}$ also results in the increase of the underdamped situation. For example, the underdamped for S7(UoD \pm 5$)$ is 
$15 \mathrm{rpm}$ and $\mathrm{S} 7(\mathrm{UoD} \pm 1)$ is $11 \mathrm{rpm}$. Thus, further increase of inputs scaling factors consequently results in the oscillation speed performance that may increase the settling time.

Simulation and experiment results are compared to understand the speed and currents behavior of the motor drive. Figure 8 shows the experiment and simulation results comparison for S7(UoD \pm 1$)$ and $\mathrm{S} 7(\mathrm{UoD} \pm 5)$ respectively. Both simulation and experiment shows a good agreement. The experiment results however shows slower response with $0.037 \mathrm{~s}$ towards the rated speed due to the encoder linearity or dynamic inertia.

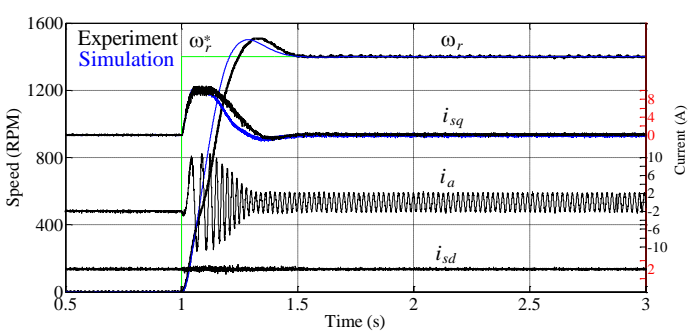

(a) $\mathrm{S} 7(\mathrm{UoD} \pm 1)$

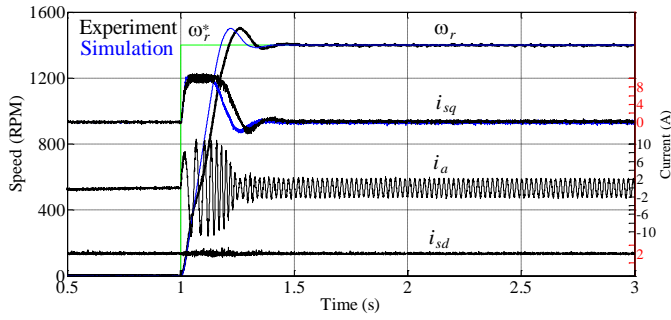

(b) $\mathrm{S} 7(\mathrm{UoD} \pm 5)$

Figure 8. Speed performance results during no load condition at 1400rpm

Table 1. Performance comparison based on no loaded experiment results

\begin{tabular}{cll}
\hline Controller & OS $(\%)$ & $\operatorname{Tr}(\mathrm{s})$ \\
\hline S7(UoD \pm 1$)$ & 7.79 & 0.208 \\
S7(UoD \pm 5$)$ & 7.43 & 0.186 \\
\hline
\end{tabular}

The rise time and settling time improve $0.022 \mathrm{~s}$ and 0.168 respectively. Higher $\mathrm{G}_{\mathrm{e}}$ values result in faster settling time speed response due to faster and higher torque current reference response. Shows details comparison of the experimental results. The $\mathrm{S} 7(\mathrm{UoD} \pm 5)$ produces faster rise time and settling time compared to $\mathrm{S} 7(\mathrm{UoD} \pm 1)$. The rise time and settling time improve $0.022 \mathrm{~s}$ and 0.168 respectively. Higher $\mathrm{G}_{\mathrm{e}}$ values result in faster settling time speed response due to faster and higher torque current reference response.

\subsection{Operation under load condition}

Further performance investigation is carried out during loaded operation. The motor was initially operated at rated speed of no load condition until 2 s before a sudden rated load is applied. Figure 9 depicts the simulation and experimental results for the load rejection performance. Almost similar behaviors between simulation and experiment results are obtained for both controllers. However, the simulation result exhibits shorter recovery time due to smooth speed drop compared to the experiment result. The experiment results experiences distortion response at the undershoot region. This distortion is due to the additional mechanical coupling effect and measurement noise in the real setup. Table 2 records the performance comparison between the controllers for simulation and experiment. Based on the result, S7(UoD \pm 5$)$ controller leads the motor performance with lowest speed drop and fastest sampling time. From the experiment result, $3.35 \%$ and $5.86 \%$ speed drop are recorded for the $\mathrm{S} 7(\mathrm{UoD} \pm 5)$ and $\mathrm{S} 7(\mathrm{UoD} \pm 1)$ respectively.

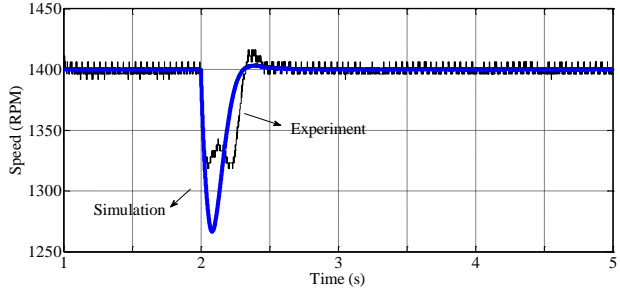

(a) $\mathrm{S} 7(\mathrm{UoD} \pm 1)$

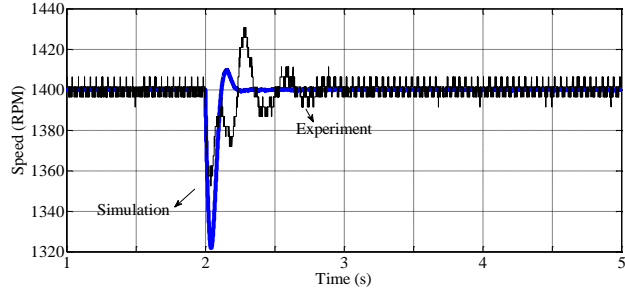

(b) $\mathrm{S} 7(\mathrm{UoD} \pm 5)$

Figure 9. Speed performance results during rated loaded condition at 1400rpm 
Table 2. Performance comparison between controllers during load disturbance operations

\begin{tabular}{cccc}
\hline Controller & Test & Speed drop (RPM) & Recover Time (s) \\
\hline S7(UoD \pm 1$)$ & Simulation & $78 \mathrm{rpm}$ & $0.116 \mathrm{~s}$ \\
S7(UoD \pm 1$)$ & Experiment & $47 \mathrm{rpm}$ & $0.235 \mathrm{~s}$ \\
S7 $(\mathrm{UoD} \pm 5$ & Simulation & $133 \mathrm{rpm}$ & $0.309 \mathrm{~s}$ \\
S7 $(\mathrm{UoD} \pm 5)$ & Experiment & $82 \mathrm{rpm}$ & $0.329 \mathrm{~s}$ \\
\hline
\end{tabular}

\subsection{Behavior Under Wide Speed Operation}

Details analysis in a wide range operation of various inputs SF controllers results are shown in Figure 10 based on the experiment results. Overall, percent overshoot behaviors shows some increment before decreasing at low speed operations. It should be noted that increasing the inputs scaling factors will increase the percent overshoot at lower speed operation region and bring the behavior curve to the left side. In general, the increase in the percent overshoots is caused by the increase in the rise time (faster response). This is the common behavior of step speed response at optimum operation [9]. The $\mathrm{S} 7(\mathrm{UoD} \pm 5)$ controller recorded the highest overshoot with $25.4 \%$ at 400rpm, followed by $\mathrm{S} 7(\mathrm{UoD} \pm 4)$ and finally $\mathrm{S} 7(\mathrm{UoD} \pm 1)$.
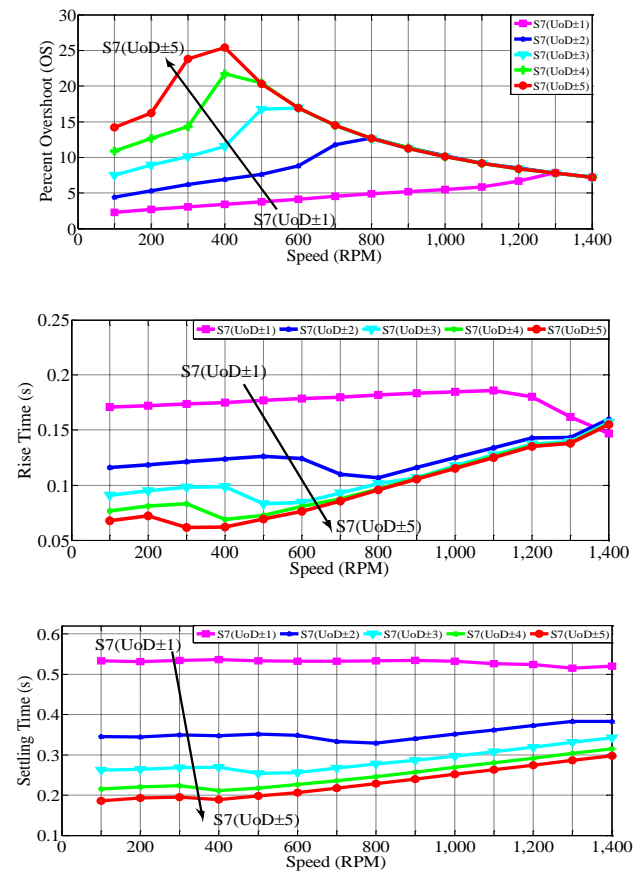

(a) Overshoot for different value of $U o D$

(b) Rise Time for different value of $\mathrm{UoD}$

(c) Settling Time for different value of UoD

Figure 10. Speed performance results during no load condition over entire speed region

Faster response is one of the important requirements of high performance speed drive. The $\mathrm{S} 7(\mathrm{UoD} \pm 5)$ recorded fastest rise time and settling time in all condition. Increase the inputs SF from 1 to 5 , significantly improves the rise time and settling in all speed operation.

\section{CONCLUSION}

This paper presents the experimental analysis of simplified rules fuzzy logic speed controller for the wide speed range operations. Details performance behaviour are carried out over wide speed range operations from zero to rated operations for various $G_{e}$ values in the range of cover from [-1,1] to [-5,5]. Based on the result, the increment of $G_{e}$ value is proportionally requires an increment of the UoD ranges. The analysis revealed that the increasing of input SF gain is able to produce faster rise time, settling time, smaller speed drop and shorter recovery time. The optimum performance is nearly achieved. Further increase of the gains however is limited by the undershoot condition and has less significant impact to the performance. In overall, the higher gains increase the percent overshoot at lower speed operation region and bring the behavior curve to the left side while tried to maintain the rise and settling time. 
Appendix A; Induction motor parameters

$R_{S}=3.45 \Omega, R_{r}=3.6141 \Omega, L_{s}=0.3252 \mathrm{H}, L_{r}=0.3252 \mathrm{H}, L_{m}=0.3117 \mathrm{H}, \mathrm{J}=0.02 \mathrm{kgm}^{2}$

\section{ACKNOWLEDGEMENT}

The authors would like to gratefully acknowledge the funding and support provided by Universiti Teknikal Malaysia Melaka (UTeM) and the Ministry of Education (MOE) Malaysia under the research grant No: FRGS/1/2015/TK04/FKE/02/F00258.

\section{REFERENCES}

[1] Saghafinia, P. Hew Wooi, M. N. Uddin, and K. S. Gaeid, "Adaptive Fuzzy Sliding-Mode Control Into ChatteringFree IM Drive," IEEE Transactions on Industry Applications, vol. 51, pp. 692-701, 2015.

[2] M. N. Uddin and J. Khastoo, "Fuzzy Logic-Based Efficiency Optimization and High Dynamic Performance of IPMSM Drive System in Both Transient and Steady-State Conditions," IEEE Transactions on Industry Applications, vol. 50, pp. 4251-4259, 2014.

[3] Y.-K. Lu, "Adaptive Fuzzy Integral Sliding-Mode Regulator for Induction Motor Using Nonlinear Sliding Surface," International Journal of Power Electronics and Drive Systems (IJPEDS), vol. 5, p. 512, 2015.

[4] L. Zheng, "A Practical Guide to Tune of Proportional and Integral (PI) like Fuzzy Controllers," in IEEE International Conference on Fuzzy Systems, 1992, pp. 633-640.

[5] F. Cupertino, A. Lattanzi, and L. Salvatore, "A New Fuzzy Logic Based Controller Design Method for DC and AC Impressed Voltage Drives," IEEE Transactions on Power Electronics, vol. 15, pp. 974-982, 2000.

[6] W. Shun-Chung and L. Yi-Hua, "A Modified PI-Like Fuzzy Logic Controller for Switched Reluctance Motor Drives," IEEE Transactions on Industrial Electronics, vol. 58, pp. 1812-1825, 2011.

[7] A. Lokriti, I. Salhi, S. Doubabi, and Y. Zidani, "Induction Motor Speed Drive Improvement using Fuzzy IP Self Tuning Controller: A Real Time Implementation," ISA Transactions, vol. 52, pp. 406-417, 2013.

[8] W. Yi, D. Huiwen, and C. Zheng, "Adaptive Fuzzy Logic Controller with Rule Based Changeable Universe of Discourse for a Nonlinear MIMO System," in 5th International Conference on Intelligent Systems Design and Applications, 2005, pp. 8-13.

[9] Z. Ibrahim and E. Levi, "A Comparative Analysis of Fuzzy Logic and PI Speed Control in High Performance AC Drives using Experimental Approach," IEEE Transactions on Industry Applications, vol. 38, pp. 1210-1218, 2002.

[10] M. N. Uddin, T. S. Radwan, and M. Azizur Rahman, "Performances of Fuzzy Logic Based Indirect Vector Control for Induction Motor Drive," IEEE Transactions on Industry Applications, vol. 38, pp. 1219-1225, 2002.

[11] Z. Jin and B. K. Bose, "Evaluation of Membership Functions for Fuzzy Logic Controlled Induction Motor Drive," in 28th Annual Conference of the Industrial Electronics Society, 2002, pp. 229-234.

[12] Z. Jin and B. K. Bose, "Membership Function Distribution Effect on Fuzzy Logic Controlled Induction Motor Drive," in 29th Annual Conference of the IEEE Industrial Electronics Society, 2003, pp. 214-219.

[13] C. B. Butt, M. Ashraful Hoque, and M. A. Rahman, "Simplified Fuzzy Logic Based MTPA Speed Control of IPMSM Drive," IEEE Transactions on Industry Applications, vol. 40, pp. 1529-1535, 2004.

[14] J.-W. Jung, H.-H. Choi, and T.-H. Kim, "Fuzzy PD speed controller for permanent magnet synchronous motors," Journal of Power Electronics, vol. 11, pp. 819-823, 2011.

[15] F. Betin, A. Sivert, A. Yazidi, and G. A. Capolino, "Determination of Scaling Factors for Fuzzy Logic Control Using the Sliding-Mode Approach: Application to Control of a DC Machine Drive," IEEE Transactions on Industrial Electronics, vol. 54, pp. 296-309, 2007.

[16] Y. Jae-Sung, K. Sang-Hoon, L. Byoung-kuk, W. Chung-Yuen, and H. Jin, "Fuzzy-Logic-Based Vector Control Scheme for Permanent Magnet Synchronous Motors in Elevator Drive Applications," IEEE Transactions on Industrial Electronics, vol. 54, pp. 2190-2200, 2007.

[17] A. Karakaya and E. Karakas, "Performance analysis of PM synchronous motors using fuzzy logic and self tuning fuzzy PI speed controls," Arabian Journal for Science and Engineering, vol. 33, pp. 153-177, 2008.

[18] S. Rafa, A. Larabi, L. Barazane, M. Manceur, N. Essounbouli, and A. Hamzaoui, "Implementation of a new fuzzy vector control of induction motor," ISA Transactions, vol. 53, pp. 744-754, 2014.

[19] R. Gunabalan and V. Subbiah, "Speed Sensorless Vector Control of Induction Motor Drive with PI and Fuzzy Controller," International Journal of Power Electronics and Drive Systems (IJPEDS), vol. 5, p. 315, 2015.

[20] C. Ming, S. Qiang, and E. Zhou, "New Self Tuning Fuzzy PI Control of a Novel Doubly Salient Permanent Magnet Motor Drive," IEEE Transactions on Industrial Electronics, vol. 53, pp. 814-821, 2006.

[21] M. H. N. Talib, Z. Ibrahim, N. A. Rahim, and A. S. A. Hasim, "Comparison Analysis of Indirect FOC Induction Motor Drive using PI, Anti-Windup and Pre Filter Schemes," International Journal of Power Electronics and Drive Systems (IJPEDS), vol. 4, pp. 219-229, 2014.

[22] M. H. N. Talib, Z. Ibrahim, N. A. Rahim, and A. S. A. Hasim, "Performance Improvement of Induction Motor Drive Using Simplified FLC Method," in 16th International Power Electronics and Motion Control Conference and Exposition, Antalya, Turkey, 2014, pp. 843-848.

[23] C. Y. Kumar B, Shrivastava V., "Efficacy of Different Rule Based Fuzzy Logic Controllers for Induction Motor Drive " International Journal of Machine Learning and Computing, vol. 2, pp. 131-137, 2012. 